\title{
HYDROGEN CYANIDE PRODUCTION IN NORTH AMERICAN AND AFRICAN POLYDESMOID MILLIPEDS ${ }^{1}$
}

\author{
By Hans E. Eisner, ${ }^{2}$ William F. Wood, ${ }^{3}$ \\ AND ThOMAS EISNER ${ }^{2}$
}

A diversity of substances has been isolated from the defensive secretions of millipeds, including hydrogen cyanide, benzaldehyde, phenols, I,4-benzoquinones, quinazolinones, and nitrogen-containing terpenes (references in Altman and Dittmer, 1973; Duffield et al., 1974; Meinwald et al., 1975; Smolanoff et al., 1975; Wood, 1974; Wood et al., 1975). Hydrogen cyanide, the first of these compounds identified (Guldensteeden-Egeling, I 882), has been reported from over a dozen European and New World species, all members of the suborder Polydesmida (Barbetta et al., 1966; Blum and Woodring, I962; Blum et al., 1973; Casnati et al., 1963; Davenport et al., 1952, Duffield $e t$ al., 1974; Eisner et al., 1963; H. E. Eisner et al., 1963; Hall et al., 1969; Monteiro, 196r). We have demonstrated hydrogen cyanide production in four additional polydesmoid species, strengthening the view that cyanogenesis may be of widespread, if not general, occurrence within the suborder. Three of the species, Apheloria trimaculata, A . kleinpeteri, and Pseudopolydesmus branneri, stemmed from the U. S. A. (the first species was from Clifton Forge, Virginia; the other two from Roanoke, Virginia); the fourth species, Astrodesmus laxus, was from Africa (Mombasa, Kenya). The animals were tested for cyanogenesis by manipulating them and gently squeezing them, while at the same time holding beside their bodies strips of filter paper impregnated with benzidine acetate-copper acetate reagent (Feigl, I966). In all instances the papers turned blue, indicating release of hydrogen cyanide vapor from their glands. In single individuals of each of the North American species, cyanogenetic output was assayed quantitively (see accompanying table), using the technique previously developed in our laboratories (H. E. Eisner et al., 1967).

\footnotetext{
${ }^{1}$ Report No. XLII of the series Defense Mechanisms of Arthropods.

${ }^{2}$ Section of Neurobiology and Behavior, Division of Biological Sciences, Cornell University, Ithaca, N. Y. 14853

${ }^{3}$ International Centre of Insect Physiology and Ecology, P. O. Box 30772, Nairobi, Kenya.
}

Manuscript received by editor February 25, 1975 
TABLE

CYANOGENETIC OUTPUT OF MILLIPEDS

\begin{tabular}{lcc}
\hline \multicolumn{1}{c}{ Species } & $\begin{array}{c}\text { Sex and Body Weight } \\
\text { of individual }\end{array}$ & $\begin{array}{c}\text { Cyanogenetic Output } \\
(\mu \mathrm{g} / \text { individual })\end{array}$ \\
\hline Apheloria trimaculata & $\sigma^{\pi}(769 \mathrm{mg})$ & 16 \\
A. kleinpeteri & $\$(1053 \mathrm{mg})$ & 27 \\
Pseudopolydesmus branneri $\sigma^{\top}(199 \mathrm{mg})$ & 32 \\
\hline \hline
\end{tabular}

Cyanogenesis in polydesmoid millipeds involves simultaneous release of hydrogen cyanide and aldehyde from stored cyanohydrin (Eisner et al., 1963). The aldehyde has been shown to be benzaldehyde in several species (Barbetta et al., 1966; Blum et al., 1973; Blum and Woodring, 1962; Casnati et al., 1963; Duffield et al., 1974; H. E. Eisner et al., 1963; Monteiro, 1961; Weatherston and Gardiner, 1973). We made no effort to isolate the aldehyde in the three North American species, but found evidence that Astrodesmus laxus produces benzaldehyde. Gas-liquid chromatography of a sample of secretion from this milliped, obtained by wiping the discharged fluid from the gland openings with pieces of filter paper, showed a peak of identical retention time to that of authentic benzaldehyde. Some polydesmoid millipeds have ancillary phenolic components in their secretion (Blum et al., 1973; Duffield et al., 1974; Monteiro, 196r). We did not attempt to isolate such components in our species, although the secretion of Pseudopolydesmus branneri had a phenolic odor.

This study was supported by grants AI-02908 and BMS-74-I 5084 from the National Institutes of Health and the National Science Foundation respectively. We thank Dr. William T. Keeton, Cornell University, for supplying and identifying the North American millipeds, and Dr. C. A. W. Jeekel, Zoologisch Museum, Amsterdam, for identifying the African species.

\section{Literature Cited}

Altman, P. L. And D. S. Dittmer.

1973. Biology Data Book, 2nd ed., vol. II (section 80, part I). Fed. Amer. Soc. Exp. Biol., Bethesda, Maryland.

Barbetta, M., G. Casnati, and M. Pavan.

1966. Sulla presenze di D-(+)-mandelonitrile nella secrezione difensiva del miriapode Gomphodesmus pavani Dem. Mem. Soc. Entomol. Ital. $45:$ 169-176. 
Blum, M. S., J. G. MacConnell, J. M. Brand, R. M. Duffield, and H. M. FALES.

1973. Phenol and benzaldehyde in the defensive secretion of a strongylosomid millipede. Ann. Ent. Soc. Amer. 66: 235.

BLUM, M. S. AND J. P. WOODRING.

1962. Secretion of benzaldehyde and hydrogen cyanide by the millipede Pachydesmus crassicutis (Wood). Science 138: 512-513.

Casnati, G., Nencini, A. Quilico, M. Pavan, A. Ricca and T. Salvatori.

1963. The secretion of the myriapod Polydesmus collaris collarsis (Koch). Experientia 19: 409-415.

Davenport, D., D. M. Wooton, and J. E. Cushing.

1952. The biology of the Sierra luminous millipede, Luminodesmus sequoiae Loomis and Davenport. Biol. Bull. 102: 100-110.

Duffield, R. M., M. S. Blum, and J. M. Brand.

1974. Guaicol in the defensive secretions of pylydesmid millipedes. Ann. Entom. Soc. Amer. 67 : 821-822.

Eisner, H. E., D. W. Alsop, And T. EIsner.

1967. Defense Mechanisms of Arthropods. XX. Quantitative Assessment of hydrogen cyanide production in two species of millipedes. Psyche 74: 107-117.

EISNer, H. E., T. Eisner, and J, J. Hurst.

1963. Hydrogen cyanide and benzaldehyde produced by millipedes. Chem. and Ind., London 1963, 124-125.

Eisner, T., H. E. Eisner, J. J. Hurst, F. C. Kafatos, and J. Meinwald.

1963. Cyanogenic glandular apparatus of a millipede. Science 139: 1218-1220.

FeIGL, F.

1966. Spot Tests in Organic Analysis. Elsevier, New York.

Guldensteeden-Egeling, C.

1882. Über Bildung von Cyanwasserstoffsäure bei einem Myriapoden. Pflügers Arch. Physiol. 28 : 576-579.

Hall, F. R., R. M. Hollingworth, and D. L. Shankland.

1969. Cyanide tolerance in millipedes and insects. Ent. News 80: 277282.

Meinwald, J., J. Smolanoff, A. McPhail, R. Miller, T. Eisner and

K. Hicks.

1975. Nitropolyzonamine: a spirocyclic nitro compound from the defensive glands of milliped (Polyzonium rosalbum). Tetrahedron Letters (in press).

Monteiro, $\mathrm{H}$.

1961. Constituents of the secretion of Orthomorpha coarctata Schubart. Anais Assoc. Brasil. Quim. $20: 29-31$.

Smolanoff, J., A. F. Kluge, J. Meinwald, A. McPhail, R. W. Miller, K. Hicks, ANd T. EISNER.

1975. Polyzonimine: a novel terpenoid insect repellent produced by a milliped. Science (in press).

Weatherston, J. and E. J. Gardiner.

1973. The defensive secretion of a polydesmoid millipede (Diplopoda). Canad. Entom. 105 : 1375-1376. 
Wood, W. F.

1974. Toluquinone and 2-methoxy-3-methylbenzoquinone from the defensive secretions of three African millipedes. Ann. Ent. Soc. Amer. 67: 988-989.

Wood, W. F., J. Shepherd, B. Chong, and J. Meinwald.

1975. Ubiquinone-o in the defensive secretion of an African millipede. Nature (in press). 

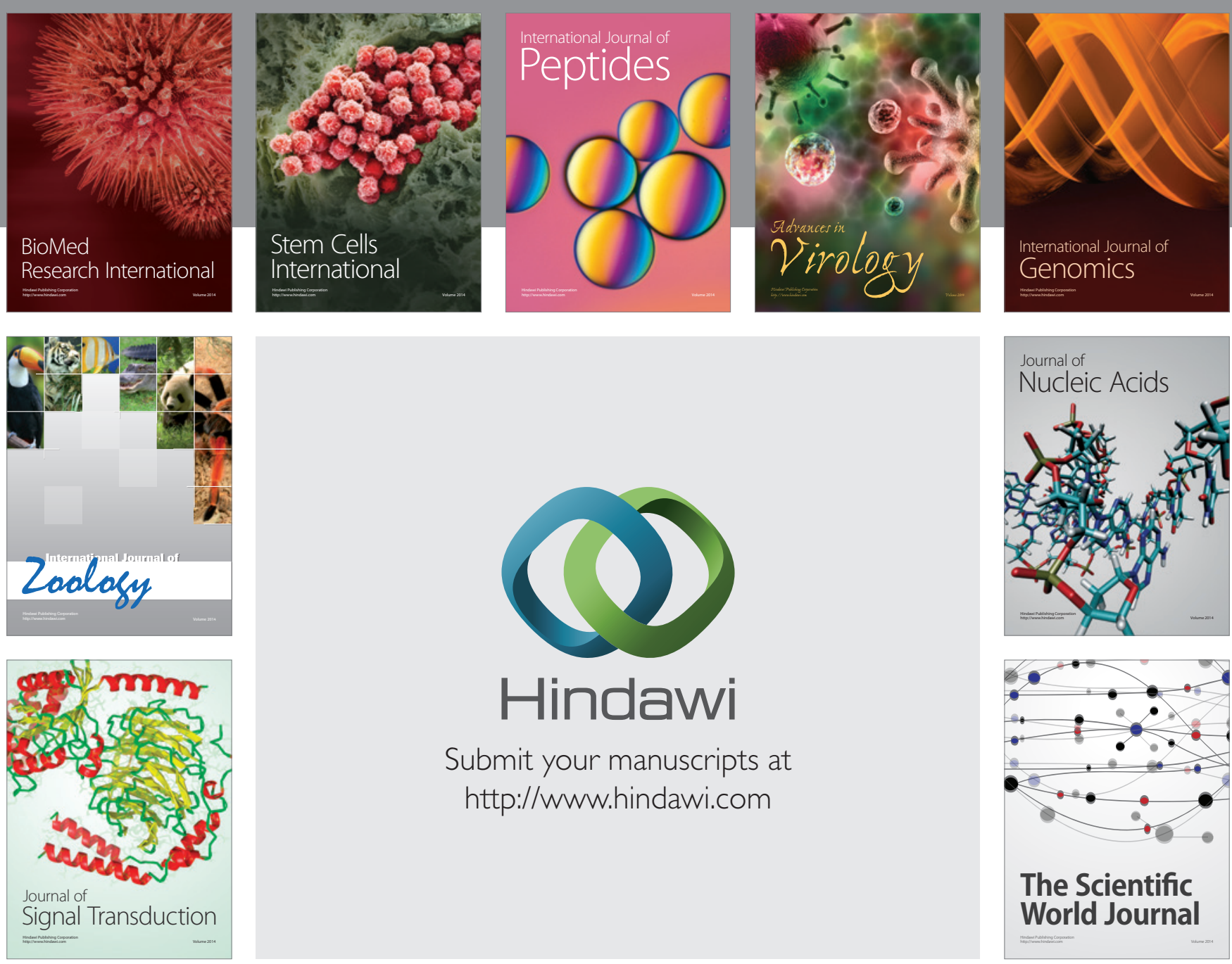

Submit your manuscripts at

http://www.hindawi.com
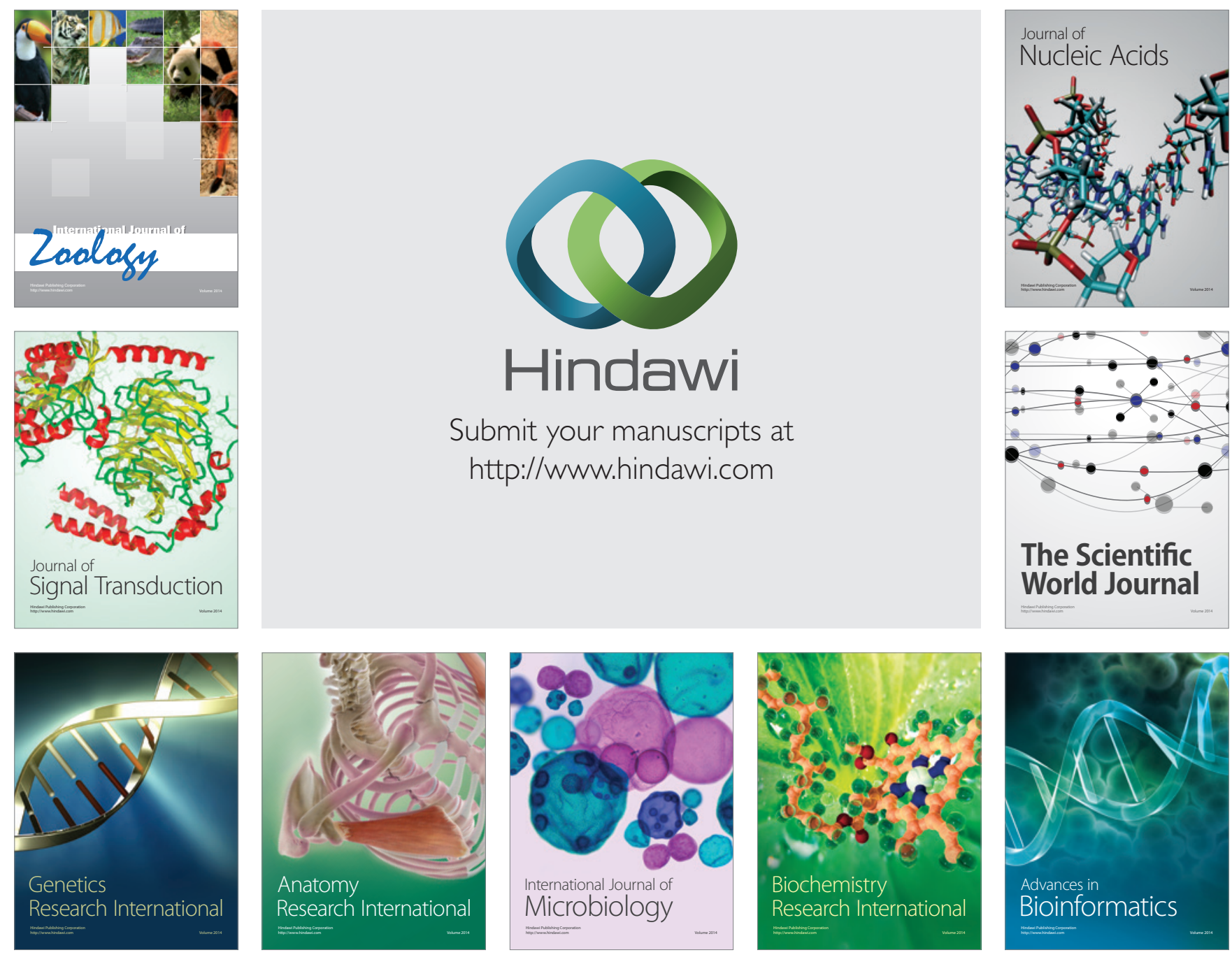

The Scientific World Journal
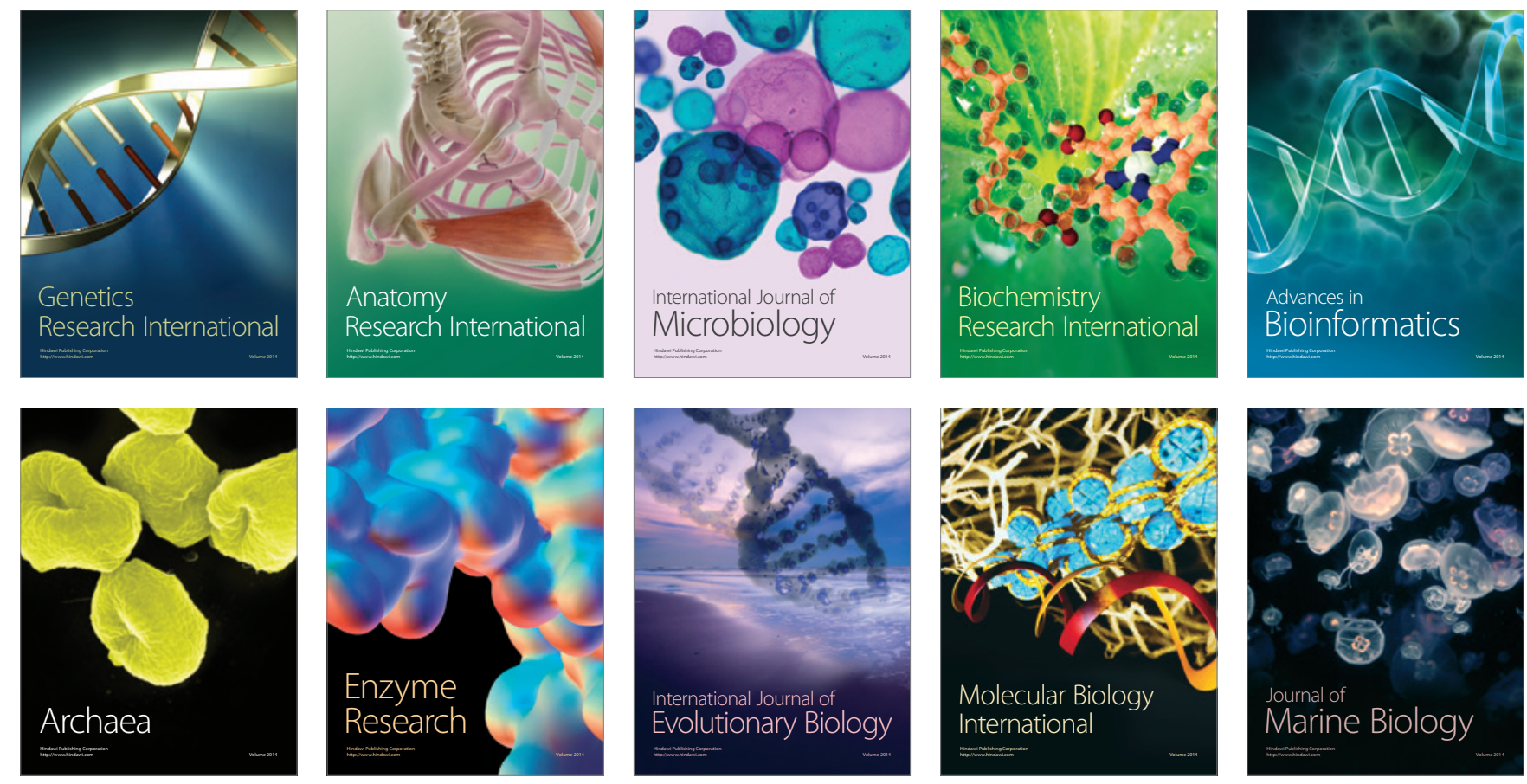